\title{
Monticellina (Polychaeta: Cirratulidae) from the Pacific coast of Costa Rica with descriptions of six new species
}

\author{
HARLAN K. DEAN ${ }^{1,3}$ \& JAMES A. BLAKE ${ }^{2}$ \\ ${ }^{\prime}$ Department of Invertebrate Zoology, Museum of Comparative Zoology, Harvard University, 26 Oxford Street, Cambridge, \\ Massachusetts02138USA.E-mail: harlan.dean@umb.edu \\ ${ }^{2}$ Marine \& Coastal Center, AECOM Environment, 89 Water Street. Woods Hole, Massachusetts 02543 USA. \\ E-mail: James.Blake@aecom.com \\ ${ }^{3}$ Corresponding author
}

\begin{abstract}
Eight species of Monticellina are described from intertidal and subtidal sites on the Pacific coast of Costa Rica. Six of these species, M. acunai sp. nov., M. antelaxa sp. nov., M. carrikeri sp. nov., M. elongata sp. nov., M. giribeti sp. nov., and M. setosa sp. nov. are new to science while M. cryptica Blake, 1996 and M. tesselata (Hartman, 1960) have been previously described from California. M. acunai sp. nov. has a wide prostomium, a peristomium with four annulations and denticulate capillary setae with numerous well-developed teeth in both the notopodium and neuropodium. $M$. antelaxa sp. nov. has a small prostomium, a wide peristomium with three annulations, and a double row of denticulate neurosetae with long fibrillar teeth. $M$. carrikeri sp. nov. has a wide prostomium, a wide peristomium with three annulations, and denticulate neurosetae with a narrow base and an expanded midsection with numerous, scattered, small teeth. M. elongata sp. nov. has a wide prostomium, an elongate peristomium with six annulations, the first segment joined with the first setiger, and denticulate capillary noto- and neurosetae with coarse teeth. $M$. giribeti sp. nov. has a wide prostomium, an elongate peristomium with five annulations, an asetigerous first segment joined with the peristomium, and denticulate capillary noto- and neurosetae with fine teeth. M. setosa sp. nov. has a small prostomium, a wide peristomium with five annulations, nuchal organs present within narrow indentations of the overlying peristomium, and denticulate capillary neurosetae with fine teeth. Morphological characteristics that may aid in the differentiation of species within the genus are discussed.
\end{abstract}

Key words: Annelida, Polychaeta, Cirratulidae, Monticellina, Costa Rica, Eastern Pacific

\section{Introduction}

The polychaetes of Costa Rica are not well known mainly due to a lack of sample effort and difficulty in the identification of what are often undescribed species. This is especially true of the Cirratulidae, a highly speciose and usually very abundant but poorly understood family. Dean (2004) lists 24 tentatively described species belonging to six genera recorded in the literature from the Pacific coast of Costa Rica. Of these, nine were identified only to the genus level. No cirratulids have been reported from the Caribbean coast of Costa Rica. Dean \& Blake (2007) presented the first thorough study of the genera Chaetozone and Caulleriella from the coast of Costa Rica and expanded the number of known members of the genus Chaetozone from two identified species to five species and the number of species of Caulleriella from one misidentified species to five. It is obvious that the family Cirratulidae has been inadequately characterized in Costa Rica. 
As part of a coordinated effort to better understand the systematics of the Cirratulidae of Costa Rica, several species of Monticellina collected from the Pacific coast are described here. Six new species-M. acunai sp. nov., $M$. antelaxa sp. nov., $M$. carrikeri sp. nov., $M$. elongata sp. nov., $M$. giribeti sp. nov., and $M$. setosa sp. nov.- are described, and the previously described species $M$. cryptica Blake, 1996 and M. tesselata (Hartman, 1960) are reported.

\section{Materials and methods}

Specimens were collected from subtidal habitats in the Gulf of Nicoya using a modified SmithMcIntyre bottom grab. Samples from Coronado Bay and Golfo Dulce were collected using a $50 \mathrm{~cm}$ $\times 50 \mathrm{~cm}$ box corer from the R/V Victor Hensen. The locations of subtidal station sites in the Gulf of Nicoya may be found in Maurer \& Vargas (1984), in Golfo Dulce in Dean (1996b) and in Coronado Bay in Morales-Ramírez (1996). Intertidal specimens were collected by the senior author or José A. Vargas (Universidad de Costa Rica). All specimens were preserved in $10 \%$ formalin and later transferred to $80 \%$ ethanol.

Type specimens of the six newly described species are deposited in the Museum of Comparative Zoology (MCZ) in Cambridge, MA, USA; paratypes and additional material are deposited in the National Museum of Natural History (USNM) in Washington, DC (USA); and paratypes are also deposited in the Zoology Museum, Universidad de Costa Rica (MZUCR), San Pedro, Costa Rica.

\section{Results}

\section{Genus Monticellina Laubier, 1961}

Type species: Monticellina heterochaeta Laubier, 1961, by monotypy.

Diagnosis (Emended). Prostomium long or short, sometimes pointed; peristomium elongated to short, with asetigerous annulations; dorsal tentacles usually arising anterior to setiger 1; middle body segments sometimes beadlike; posterior segments usually expanded or enlarged. Setae include capillaries with distinct sawtooth (denticulate) edge, often basally expanded.

\section{Monticellina acunai sp. nov.}

Figures 1A-F, 3A, 6D

Monticellina cryptica: Dean 2004:140 (in part).

Monticellina secunda: Dean 2004:140.

Monticellina tesselata: Dean 2004:140.

Tharyx parvus: Vargas et al. 1985:335 (in part); Maurer et al. 1988:46; Dean 1996a:72.

Tharyx tesselata: Vargas et al. 1985: 335 (in part); Dean 1996a:72.

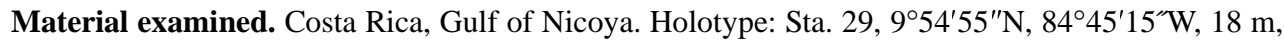
muddy sand, 27 Jan 1981 (MCZ 83356). Paratypes: Sta. 14, 9 $57^{\prime} 05^{\prime \prime} \mathrm{N}, 8^{\circ} 45^{\prime} 30^{\prime \prime} \mathrm{W}, 9 \mathrm{~m}$, sandy

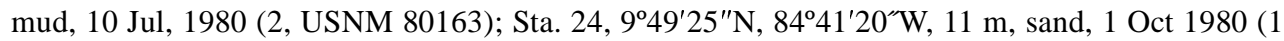
MZUCR 176-01); Sta. 29, 9 $54^{\prime} 55^{\prime \prime} \mathrm{N}, 84^{\circ} 45^{\prime} 15^{\prime \prime} \mathrm{W}, 18 \mathrm{~m}$, muddy sand, 4 Aug 1981 (1, MCZ 83357): Sta. $31,9^{\circ} 54^{\prime} 40^{\prime \prime} \mathrm{N}, 8^{\circ} 45^{\prime} 50^{\prime \prime} \mathrm{W}, 18 \mathrm{~m}$, muddy sand, 11 Jul, 1980 (1, USNM 80165). 
Comparative material examined. Costa Rica, Gulf of Nicoya. Sta. 1, 957'30"N, 84 $53^{\circ} 00^{\prime \prime} \mathrm{W}$, 46 m, mud, 10 Jul, 1980 (2, USNM 80159 + 1, USNM 80160). Sta. 24, 949'25"N, 8441'20"W, 11 m, sand, 1 Oct 1980 (68, HKD); 27 Jan 1981 (1, HKD). Sta. 28, 952'16"N, 8445'30"W, 26 m, mud,

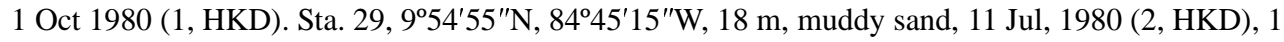
Oct, 1980 (4, HKD), 27 Jan 1981 (19, HKD), 7 Jun 1981 (1, HKD), 7 Jun 1981 (3, HKD), 4 Aug 1981 (23, HKD). Sta. 30, 954'40"N, 8445'50"W, 18 m, muddy sand, 27 Jan 1981 (1, HKD). Sta. $38,9^{\circ} 57^{\prime} 15^{\prime \prime} \mathrm{N}, 84^{\circ} 50^{\prime} 35^{\prime \prime} \mathrm{W}, 7$ m, (1, USNM 80142). Costa Rica, Coronado Bay. Sta. 04, 847'N, 834'ㄴ, 20 m, 6 Dec 1993 (1, HKD) (coll.: José A. Vargas).
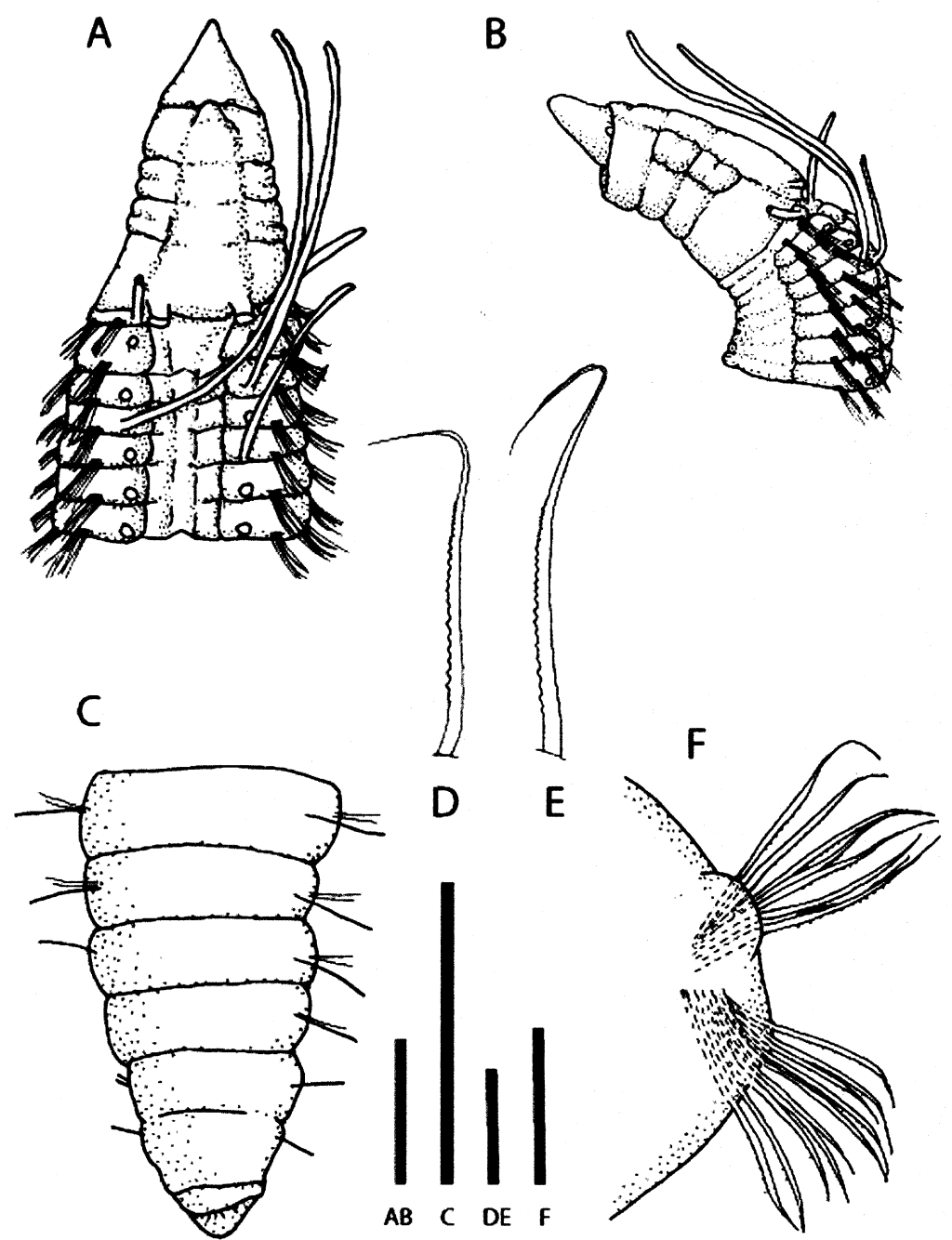

FIGURE 1. Monticellina acunai sp. nov. A, dorsal view of anterior end; B, lateral view of anterior end; C, pygidium, dorsal view; D, denticulate posterior neurosetae; E, denticulate posterior notoseta; F, posterior setiger, anterior view. Scale bars: $A, B=0.2 \mathrm{~mm} ; C=0.2 \mathrm{~mm} ; \mathrm{D}, \mathrm{E}=20 \mu \mathrm{m} ; \mathrm{F}=50 \mu \mathrm{m}$. 
Description. A moderate-sized species, holotype $15.7 \mathrm{~mm}$ long, body uniformly $0.4 \mathrm{~mm}$ wide for 64 setigers (MCZ 83356), thoracic region 19 setigers; complete paratype $12.3 \mathrm{~mm}$ long, $0.4 \mathrm{~mm}$ wide anteriorly, $0.2 \mathrm{~mm}$ wide posteriorly for 86 setigers (USNM 80165); incomplete paratypes 42.7 $\mathrm{mm}$ long, $0.4 \mathrm{~mm}$ wide anteriorly, $0.8 \mathrm{~mm}$ wide in posterior for 105 setigers (MZUCR 176-01 ); 15.0 $\mathrm{mm}$ long, $0.4 \mathrm{~mm}$ wide in thoracic region, $0.3 \mathrm{~mm}$ wide in posterior for 54 setigers (MCZ 89957). Body long, narrow, thoracic segments much wider than long, middle and posterior segments as long as wide. Thoracic notopodial lobes elevated, forming narrow middorsal trough, with dorsum of thorax flattened, but with raised middorsal ridge present, most prominent in anterior thoracic segments, reduced in posterior of thorax segments; ventral surface of thorax rounded without groove. Middle and posterior setigers rounded in cross section. Setal fascicles emerge dorsolaterally from low tori in thoracic region, and laterally in remainder of body. Pygidium of paratype (USNM 80165) conical, anus dorsal (Fig. 1C); holotype with cirriform ventral extension, apparently regenerating. Color in alcohol light tan.

Prostomium wide, triangular, paired nuchal organs present at posterolateral border. Peristomium $1.2 \times$ as long as wide; weakly annulated with elevated dorsal ridge and short anterior dorsal projection extending anteriorly over posterior border of prostomium (Figs. 1A-B, 3A); four asetigerous annulations present, with two median annulations subequal in length to first, each with bilobed swellings at lateral border of middorsal crest, fourth annulation approximately $2 \times$ length of others. Dorsal tentacles arising from posterior margin of fourth annulation; first branchiae on setiger 1, lateral and slightly posterior to dorsal tentacles, dorsal to notosetal fascicle; subsequent thoracic branchiae emerge from posteromedial border of expanded notopodial lobe at edge of dorsal trough; branchiae of middle and posterior setigers emerging adjacent to notosetal fascicles; branchiae continuing to posterior setigers.

Notosetae include 4-7 fimbriated capillaries in thoracic setigers, replaced by 8-12 strongly serrated capillaries in middle and posterior setigers (Fig. 1E), serrated notosetae from setiger 22 in holotype and setigers 34 and 23 in paratypes (MZUCR 176-01 \& MCZ 83357); notosetae arranged in two rows, with those of anterior row shorter than those of posterior row (Fig. 1F). Neurosetae 5-8 short, fimbriated capillaries in anterior setigers, replaced by $8-10$ strongly serrated capillaries in middle and posterior setigers (Figs. 1D, 6D); serrated capillaries from setiger 22 in holotype, and setigers 33 and 21 in paratypes (MZUCR 176-01 \& MCZ 83357). Thoracic notosetae slightly longer than neurosetae (setal length ratio of notosetal to neurosetal length: 1.3), those of remainder of body coequal (setal length ratio: 1.1), serrations of neurosetae coarser and more widely spaced than those of notosetae (Fig. 1 D-E).

Methyl green staining. Body staining light blue; prostomium and pygidium not staining, with granular blue bands extending across venter of setigers 10-16, less distinct bands in more anterior setigers, thin, darkly staining midventral longitudinal lines beginning posterior to thoracic setigers, peristomium with paired thin blue lines along lateral borders of middorsal ridge.

Habitat. Monticellina acunai sp. nov. is the most commonly collected subtidal species of the genus in the Gulf of Nicoya, occurring in mud to sand sediments at depths of 9-46 m.

Remarks. Monticellina acunai sp. nov. has long narrow denticulate noto- and neurosetae similar to those in M. dorsobranchiata (Kirkegaard, 1959), M. elongata sp. nov. and M. setosa sp. nov. The broad, conical prostomium is similar to that of $M$. elongata sp. nov. but the elongate peristomium with six annulations of $M$. elongata sp. nov. is much different from the shorter peristomium of $M$. acunai sp. nov., which has four annulations. The raised middorsal ridge is shared with only $M$. tesselata but that species has short, wide, denticulate setae and the morphology of the prostomium and peristomium are very different.

Etymology. This species is named in honor of Jenaro A. Acuña-González, marine chemist at 
Centro de Investigación en Ciencias del Mar y Limnología (CIMAR) San Jose, Costa Rica for his support and friendship during numerous collecting trips to Costa Rica by the senior author.

Monticellina antelaxa sp. nov.

Figures 2A-D, 6A

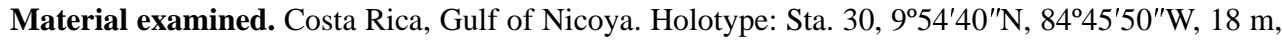
muddy sand, 1 Oct. 1980 (MCZ 83358).

Description. A moderate-sized species, incomplete holotype $11.4 \mathrm{~mm}$ long, $1.2 \mathrm{~mm}$ maximum thoracic width, post-thoracic region $0.5 \mathrm{~mm}$ wide, for 73 setigers. Thoracic region dorsoventrally flattened, approximately 40 setigers long, setigers 15-20× wider than long, with weakly inflated dorsolateral parapodial lobes. Post-thoracic region oval in cross section, setigers approximately onehalf as long as wide, setal bundles positioned laterally, emerging directly from body wall. Pygidium absent. Color pale tan in alcohol.

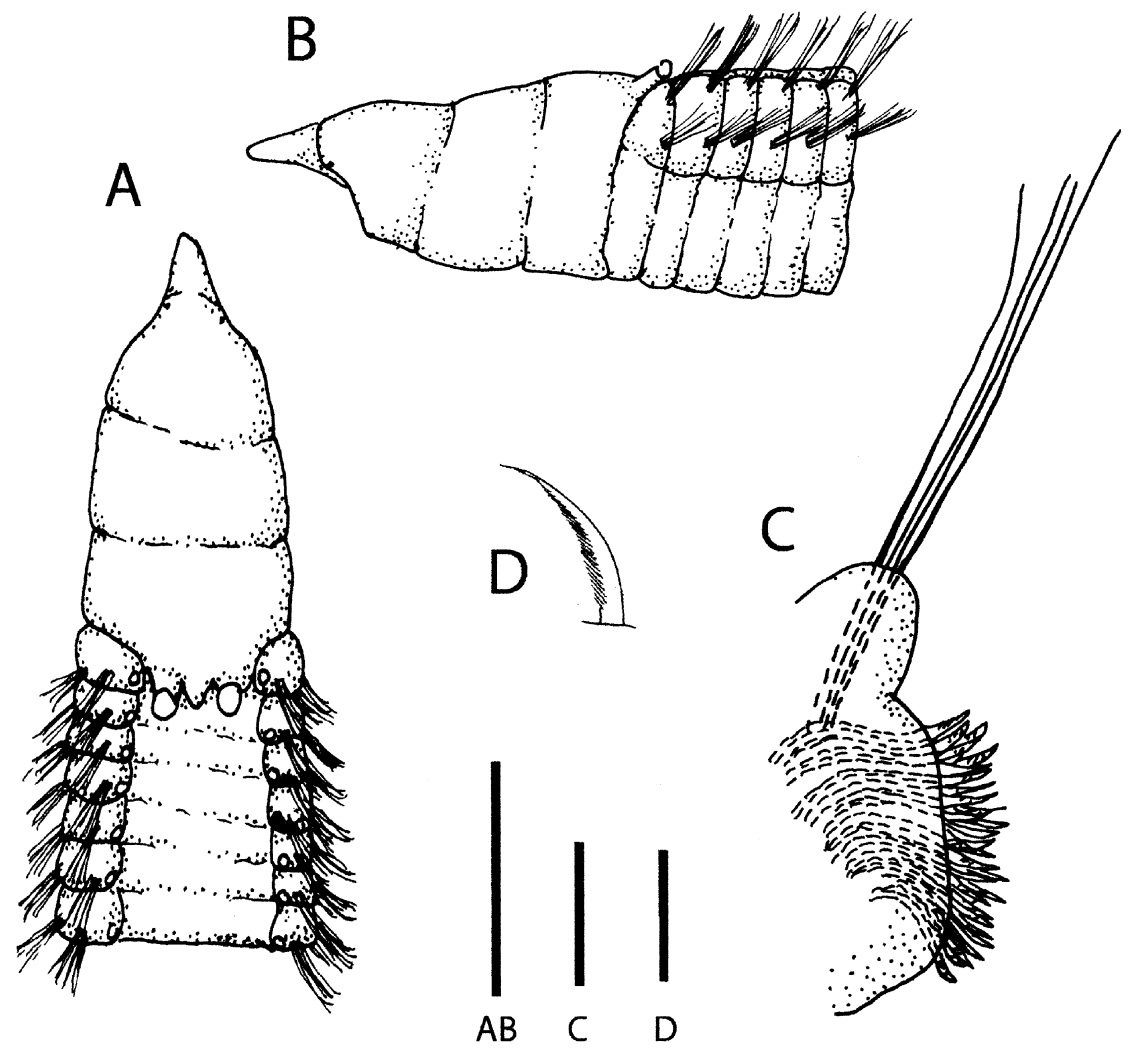

FIGURE 2. Monticellina antelaxa sp. nov. A, dorsal view of anterior end; B. lateral view of anterior end; C, posterior setiger, anterior view; $\mathrm{D}$, denticulate posterior neuroseta. Scale bars: $\mathrm{A}, \mathrm{B}=0.5 \mathrm{~mm}$; C $=50 \mu \mathrm{m}$; D $=20 \mu \mathrm{m}$. 
Prostomium conical, rounded on narrow anterior margin; with small, paired nuchal organs present dorsolaterally at posterior borders, peristomium overlapping posterior margin of prostomium (Fig. 2 A-B). Peristomium $1.3 \times$ as long as wide; with three subequal asetigerous annulations, posterior border of last annulation extending over dorsum of setiger 1. Dorsal tentacles emerging from posterior border of peristomium; first branchiae on setiger 1 dorsal to notosetal bundle, posterolateral to dorsal tentacles, subsequent branchiae similar in position throughout (Fig. 2A).

Notosetae all capillaries with 4-10 capillaries in anterior fascicles of thorax, increasing to 19 capillaries per fascicle in mid-thoracic region, then decreasing to 6-10 capillaries in posterior thorax and beginning of post-thoracic region; rapidly decreasing to 3-6 smooth capillaries in posterior segments (Fig. 2C). Neuropodia of anterior setigers with three short and five long capillaries, increasing to eight long, weakly serrated capillaries and six short, serrated capillaries in mid-thoracic region (setiger 34); in posterior thoracic region neurosetae reduced to 4-6 short, weakly serrated and 6-8 short, strongly serrated setae with broad blades; in post-thoracic region neurosetae rapidly increasing to double row of approximately 30 short, strongly serrated setae with broad, blade-like setae bearing long fibril-like teeth (Figs. 2C-D, 6A). Ratio of notosetal to neurosetal length:1.3 in thorax, 11.0 in abdomen.

Methyl green staining. Body staining a uniform light blue; anterior tip of prostomium does not stain.

Habitat. Monticellina antelaxa sp. nov. is known only from muddy sand from $18 \mathrm{~m}$ in the Gulf of Nicoya. The specimen is a gravid female containing numerous eggs of variable size (maximum $100-130 \mu \mathrm{m})$ and shape (irregularly oval) within the body cavity.

Remarks. The long double row of broad posterior thoracic neurosetae with elongate, fibrillar dentitions differentiates Monticellina antelaxa sp. nov. from all other described species in this genus. The broad peristomium with three annulations is similar to that of $M$. carrikeri sp. nov. but the prostomium is relatively larger in $M$. carrikeri sp. nov. The peristomium is similarly broad and the prostomium is small in M. secunda (Banse \& Hobson, 1968), but this species has only two annulations and very different setae.

Etymology. The specific name is from the Latin ante meaning anterior and the Latin laxus meaning wide and refers to the broad thoracic region relative to the narrower posterior body region.

\section{Monticellina carrikeri sp. nov.}

Figures 3B, 4A-E, 6C

Monticellina cryptica: Dean 2004:140 (in part).

Monticellina secunda: Dean 2004:140 (in part).

Monticellina sp. A: Dean 1996a:72.

Tharyx parvus: Vargas et al. 1988:335.

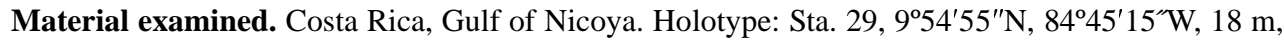
muddy sand, 27 Jan 1981(MCZ 83359). Paratype: same sample (1, MZUCR 177-01).

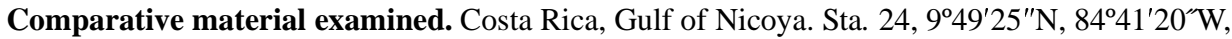

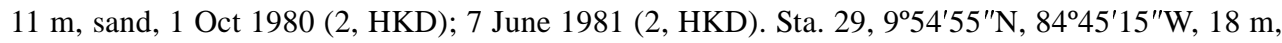
muddy sand, 27 Jan 1981 (24, HKD), 4 Apr 1981 (2, HKD). Sta. 30, 954'40”N, 8445'50`W, 18 m, muddy sand, 27 Jan 1981 (1, HKD). Sta. 32, 953'47"N, 8449'35"W, 24 m, mud/sand, 11 Jul 1980 (1, USNM 80154).

Description. Holotype $7.8 \mathrm{~mm}$ long, thorax and swollen posterior region $0.3 \mathrm{~mm}$ wide, mid- and 
posterior body regions $0.2 \mathrm{~mm}$ wide, with 81 setigers. Paratype $9.8 \mathrm{~mm}$ long, thorax $0.4 \mathrm{~mm}$ wide, $0.2 \mathrm{~mm}$ wide in mid and posterior setigers, swollen posterior end $0.3 \mathrm{~mm}$ wide, for 119 setigers. Body long, threadlike, thoracic region slightly flattened dorsoventrally, thoracic setigers approximately $11 \times$ wider than long with raised notopodial tori; swollen posterior end weakly flattened dorsoventrally with shallow ventral groove, setigers narrow, approximately $9 \times$ as wide as long; remainder of body cylindrical with segments approximately $2.5 \times$ as wide as long, closely spaced notopodial and neuropodial fascicles emerging dorsolaterally from body surface. Pygidium with cone-shaped terminal papilla (Fig. 4C). Color in alcohol white.

Prostomium triangular, with narrow, rounded anterior end, paired nuchal organs dorsolaterally at posterior border beneath overlapping peristomium (Figs. 3B, 4A-B). Peristomium 1.1 times as long as wide; with three subequal asetigerous annulations, third annulation extending posteriorly over dorsum of setiger 1, annulations less obvious on swollen dorsal crest. Paired dorsal tentacles emerging from posterior border of last annulation; first branchiae on setiger 1, dorsal to notopodial setal bundle and lateral to dorsal tentacles; subsequent branchiae at posterior-medial border of raised notopodial lobes in thoracic setigers, posterior to notosetal bundle in posterior setigers (Fig. 4A).

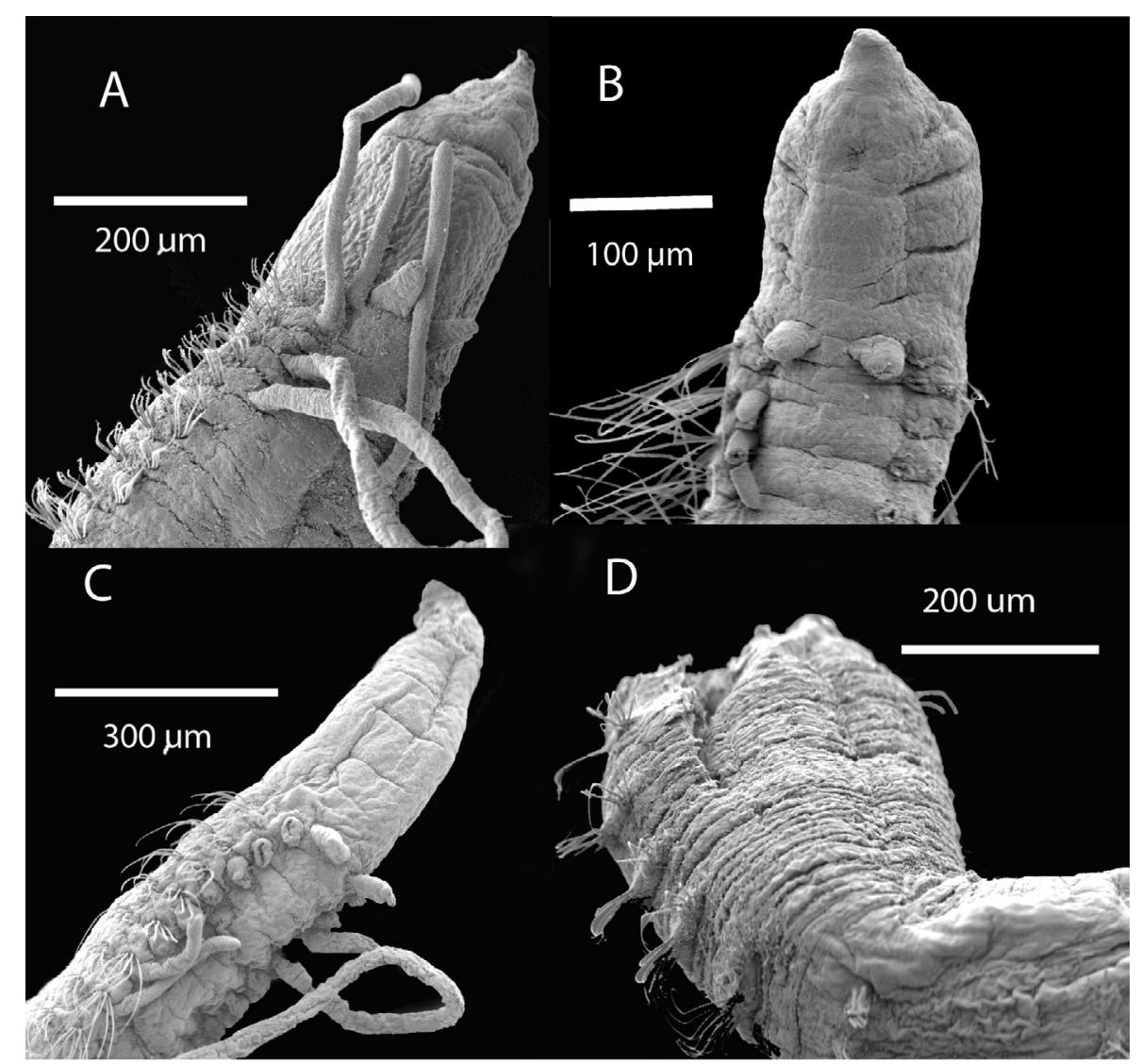

FIGURE 3. Monticellina acunai sp. nov. A, anterior end, dorsal view. Monticellina carrikeri sp. nov. B, anterior end, dorsal view. Monticellina elongata sp. nov. C, anterior end, dorsolateral view; D, expanded posterior end. 
Notosetae smooth capillaries throughout, 4 or 5 setae per fascicle in thoracic region, 2-6 in middle and posterior setigers, and two in far posterior setigers. Thoracic neurosetae 3-4 flat-bladed capillaries per setal fascicle bearing small marginal dentations; 2-4 subdistally widened neurosetae in middle and posterior regions; with numerous small denticulations present on capillaries from setiger 31-33 (Figs. 4D-E, 6C). Setal length ratio: 1.0 in thorax, 3.3 in abdomen.

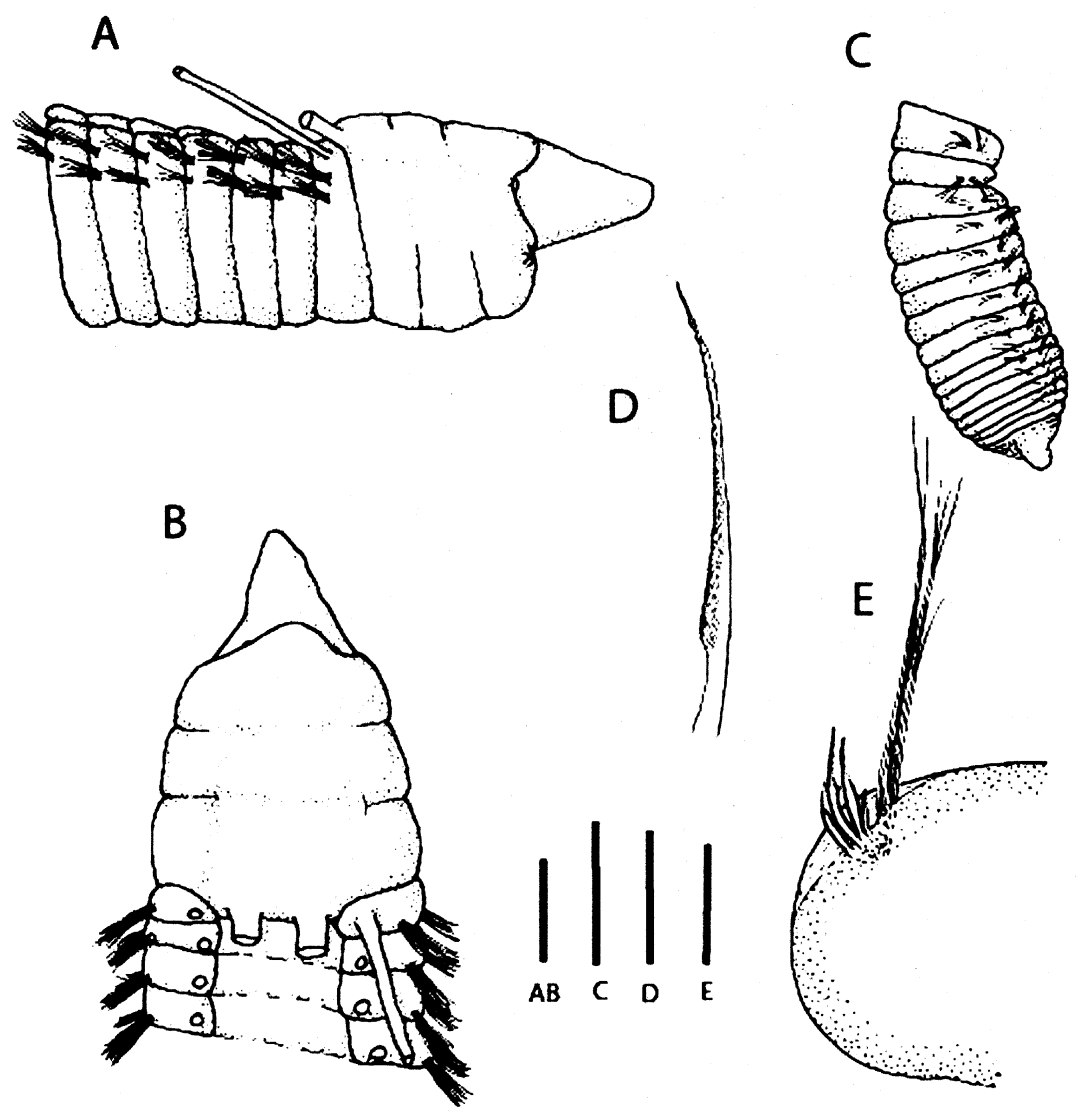

FIGURE 4. Monticellina carrikeri sp. nov. A, lateral view of anterior end; B, dorsal view of anterior end; C, expanded posterior region, lateral view; $\mathrm{D}$, denticulate posterior neuroseta; E, posterior setiger, anterior view. Scale bars: A, B $=0.1 \mathrm{~mm} ; \mathrm{C}=0.2 \mathrm{~mm} ; \mathrm{D}=10 \mu \mathrm{m} ; \mathrm{E}=50 \mu \mathrm{m}$.

Methyl green staining. Prostomium, peristomium, and last 25-30 setigers not staining, with narrow blue transverse bands across venter of thoracic setigers; remainder of body uniformly bluegreen.

Habitat. Monticellina carrikeri sp. nov. was collected subtidally in the Gulf of Nicoya in sand or muddy sand from 11-24 m.

Remarks. Monticellina carrikeri sp. nov. is most similar to M. tesselata based upon their basally narrow but medially broad denticulate setae and a wide peristomium. $M$. carrikeri sp. nov. differs from $M$. tesselata in the relative size of the prostomium and in having a peristomium with three annulations instead of two and by lacking a middorsal thoracic ridge. 
Etymology. This species is named for the late Dr. Melbourne R. Carriker, who not only aided both authors in their careers in biology but also served as a valuable mentor in life to the first author.

\section{Monticellina cryptica Blake 1996}

Figure 5A-E

Monticellina cryptica Blake 1996: 319-321: Dean 2004:140 (in part).

Tharyx sp. B: Dean 1996a:72.

Material examined. Costa Rica, Gulf of Nicoya. Sta. 24, $9^{\circ} 49^{\prime} 25^{\prime \prime} \mathrm{N}, 84^{\circ} 41^{\prime} 20^{\prime \prime} \mathrm{W}, 11 \mathrm{~m}$, sand, 1 Oct 1980 (1, MZUCR 177-02).
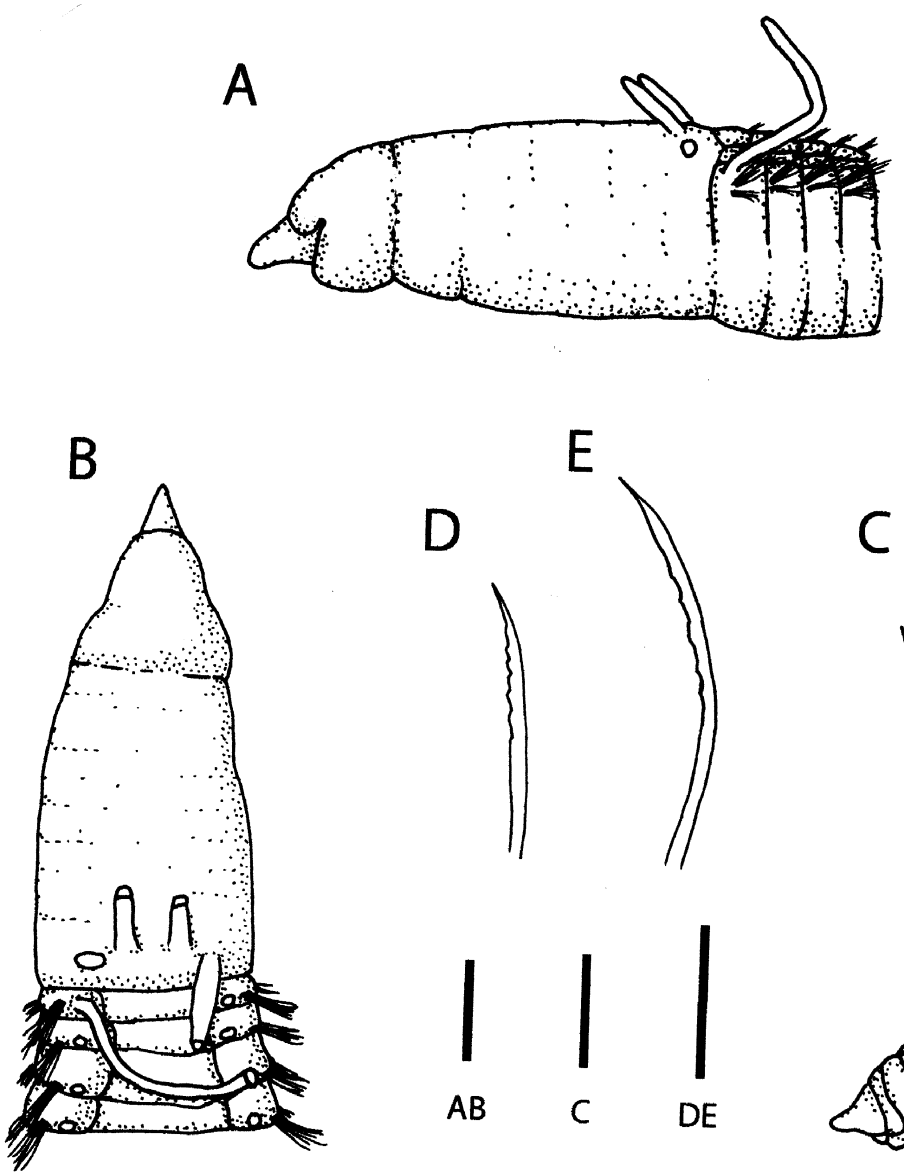

E
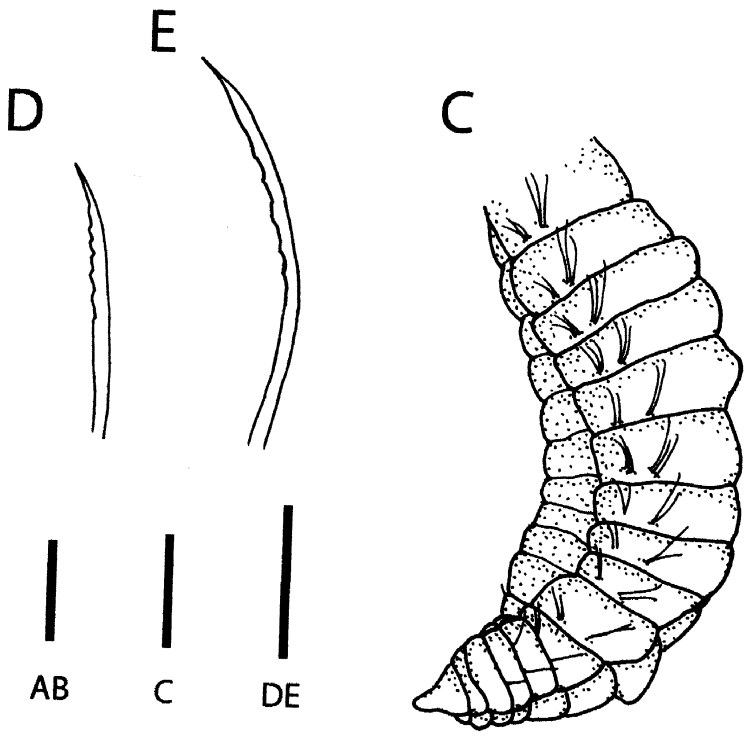

FIGURE 5. Monticellina cryptica Blake, 1996. A, lateral view of anterior end; B, dorsal view of anterior end; $\mathrm{C}$, lateral view of expanded posterior region; $\mathrm{D}$, denticulate posterior neuroseta; $\mathrm{E}$, denticulate posterior notoseta. Scale bars: A, B $=0.1 \mathrm{~mm} ; \mathrm{C}=0.1 \mathrm{~mm} ; \mathrm{D}, \mathrm{E}=20 \mu \mathrm{m}$. 
Description. Specimen complete, $8.76 \mathrm{~mm}$ long, thorax and posterior setigers $0.3 \mathrm{~mm}$ wide, mid-body $0.6 \mathrm{~mm}$ wide, for 69 setigers. Body long, narrow with expanded mid-body; thoracic region flattened dorsally, middle and posterior setigers cylindrical in cross section; posterior region weakly expanded, ventrally concave with a weak dorsomedial groove; thoracic parapodial lobes slightly elevated forming shallow dorsal trough. Pygidium with small conical papilla (Fig. 5C). Color white in alcohol.

Prostomium short, pointed anteriorly, with paired nuchal organs dorsolaterally, within notch below overlying peristomium; peristomium $1.7 \times$ as long as wide; with two asetigerous annulations, second annulation approximately $3 \times$ as long as first (Fig. 5A-B). Dorsal tentacles emerging from posterior end of second annulation, first pair of branchiae arising slightly posterior and lateral to dorsal tentacles on asetigerous first body segment fused to peristomium (Fig. 5B); subsequent branchiae dorsal to notosetal fascicles at posterior border of each setiger.

Thoracic parapodia low-lying ridges with emergent setal bundles; elsewhere parapodial lobes weak lateral swellings, setal bundles emerging laterally. Notosetae and neurosetae simple fimbriated capillaries in thorax, becoming more flattened with widely spaced short teeth along cutting edge in abdominal segments (Fig. 5DE). Setal length ratio: 1.0 in thoracic setigers and 2.0 in abdominal setigers.

Methyl green staining. Body staining uniform green, prostomium and expanded posterior region not staining.

Habitat. The complete specimen of $M$. cryptica was collected in sand and an incomplete posterior fragment was collected in muddy sand at depths of 11-18 $\mathrm{m}$ in the Gulf of Nicoya. Blake (1996) recorded this species from shelf and upper slope depths of 92-585 m off central California.

Remarks. This specimen agrees closely with Blake's (1996) original description although the anterior annulation of the peristomium was not described. The elongate peristomium and the presence of the first branchiae on the peristomium behind the dorsal tentacles are unusual. The dorsal groove between the elevated parapodia in the thoracic region is not seen as clearly here as in the type material. The serrated noto- and neurosetae with widely spaced teeth is an important species-level character.

\section{Monticellina elongata sp. nov.}

Figures 3C-D, 7A-E

Monticellina cryptica: Dean 2004:140.

Monticellina secunda: Dean 2004:140 (in part).

Monticellina tesselata: Dean 1996a:72 (in part).

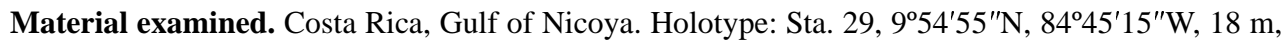
muddy sand, 1 Apr 1982 (MCZ 83361). Paratypes: Sta. 3, 9 $9^{\circ} 52^{\prime} 00^{\prime \prime} \mathrm{N}, 8^{\circ} 48^{\prime} 10^{\prime \prime} \mathrm{W}, 33 \mathrm{~m}$, sandy

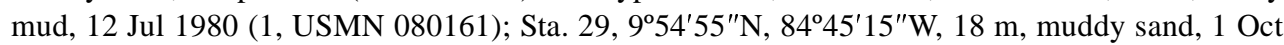
1980 (1, MCZ 83362); 27 Jan 1981 (1 SEM preparation, MCZ 83360); 4 Apr 1981 (1, MZUCR 177-03).

Comparative material examined. Costa Rica, Gulf of Nicoya. Sta. 29 , 9 ${ }^{\circ} 54^{\prime} 55^{\prime \prime} \mathrm{N}, 84^{\circ} 45^{\prime} 15^{\prime \prime} \mathrm{W}$, 18 m, muddy sand, 1 Apr 1982 (2, HKD).

Description. Holotype incomplete, $10.9 \mathrm{~mm}$ long, $0.4 \mathrm{~mm}$ maximum width for 45 setigers; incomplete paratypes $5.1 \mathrm{~mm}$ long, $0.3 \mathrm{~mm}$ wide anteriorly, $0.4 \mathrm{~mm}$ wide at swollen posterior, for 46 setigers (MCZ 83360); $6.2 \mathrm{~mm}$ long, $0.3 \mathrm{~mm}$ wide anteriorly, mid-body $0.5 \mathrm{~mm}$ wide for 46 setigers 
(MZUCR 177-03); $3.6 \mathrm{~mm}$ long, $0.4 \mathrm{~mm}$ wide anteriorly, for 29 setigers (MCZ 83360). Thorax slightly flattened dorsoventrally, remainder of body cylindrical in cross section; swollen posterior region dorsoventrally flattened. Thoracic region with 20 crowded segments, $4 \times$ as wide as long; middle and posterior setigers $2 x$ as wide as long; expanded posterior end of approximately seven setigers (Fig. 3D), $4 \times$ as wide as long with pair of ventrolateral grooves. Pygidium not present. Color in alcohol brown to white (in small specimen).

Prostomium conical, with paired nuchal organs at posterolateral borders (Figs. 3C, 7A-B). Peristomium cylindrical, $2.3 \times$ as long as wide; with six subequal asetigerous annulations and weak dorsal crest. Paired dorsal tentacles emerging from posterior border of peristomium; first pair of branchiae posterolateral to tentacles on asetigerous first segment fused to setiger 1 (Fig. 7B), subsequent branchiae dorsal to notosetal bundles on all setigers (including setiger one).
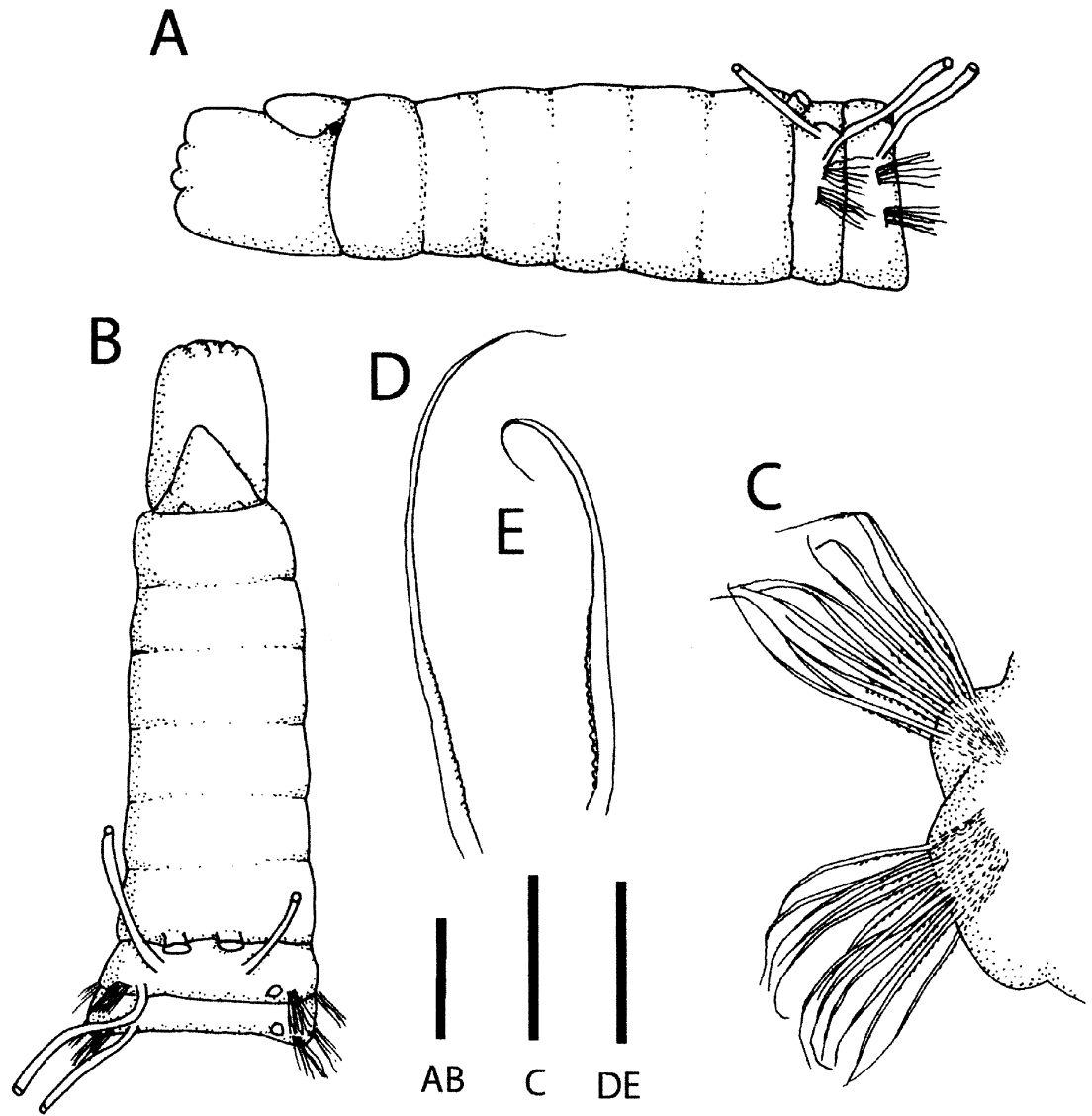

FIGURE 7. Monticellina elongata sp. nov. A, lateral view of anterior end; B, dorsal view of anterior end; C, posterior setiger, anterior view; D, denticulate posterior notoseta; E, denticulate posterior neuroseta. Scale bars: $\mathrm{A}, \mathrm{B}=0.2 \mathrm{~mm}$; C $=50 \mu \mathrm{m} ; \mathrm{D}, \mathrm{E}=20 \mu \mathrm{m}$.

Thorax with 5-7 smooth, blade-like capillary notosetae arranged in two rows; 8-16 blade-like capillaries arranged in irregular oval fascicles in middle and posterior body segments (Fig. 7C), with weakly toothed capillaries from setiger 24 (25 in MZUCR-177-03). Thoracic neurosetae 6-10 
blade-like capillaries arranged in two rows, increasing to 10-16 in middle and posterior body regions (Fig. 7C); toothed capillaries from setiger 22 ( 24 in MZUCR 177-03). Serrated setae of both rami with proximal serrated region and elongate, smooth distal region (Fig. 7DE); teeth of neurosetae more pronounced than those of notosetae. Setal length ratio: 1.3 in thorax, 1.1 in abdomen.

Methyl green staining. Body with green stripe across venter at anterior margin of setigers 11-23; most of body staining uniformly green, with prostomium and peristomium staining more lightly.

Habitat. Collected from muddy sand at $18 \mathrm{~m}$.

Remarks. Monticellina elongata sp. nov. seems to be most similar to M. giribeti sp. nov. The elongate peristomium of $M$. elongata sp. nov. is most similar to that of both $M$. giribeti sp. nov. and $M$. cryptica but $M$. elongata sp. nov. has six annulations of the peristomium while $M$. giribeti sp. nov. has five and $M$. cryptica has only two. M. elongata sp. nov. has the first segment (based upon the presence of the first pair of branchiae) joined to the first setiger (with its own pair of branchiae) while $M$. giribeti sp. nov. has the first segment joined with the peristomium. The prostomium of $M$. elongata sp. nov. and $M$. giribeti sp. nov. are similarly broad and the thin, finely denticulate notosetae and neurosetae are also similar. The blade-like denticulate setae of $M$. cryptica with its widely spaced, fine teeth is much different from those of M. elongata sp. nov. and M. giribeti sp. nov.

Etymology. The species name is in reference to the elongate peristomium of this species.

\section{Monticellina giribeti sp. nov.}

Figures 6B, 8A-F

Tharyx parvus: Vargas 1987:304; Dean 2004:141.

Material examined. Costa Rica, Gulf of Nicoya. Holotype: Punta Morales, Playa Blanco, lower intertidal, muddy sand, Dec 1985, (MCZ 77777) (coll.: José A. Vargas). Paratype: same sample (MZUCR 178-01).

Comparative material examined. Gulf of Nicoya. Punta Morales, Playa Blanco, lower intertidal, muddy sand, 16 Dec 1985 (3, HKD) (coll.: José A. Vargas).

Description. Holotype complete, $18.5 \mathrm{~mm}$ long, $0.4 \mathrm{~mm}$ wide in thoracic region, $0.5 \mathrm{~mm}$ wide in mid-body, $0.3 \mathrm{~mm}$ wide posteriorly, swollen posterior end $0.6 \mathrm{~mm}$ wide, for 92 setigers; incomplete paratypes $11.7 \mathrm{~mm}$ long, $0.3 \mathrm{~mm}$ width of thoracic region, $0.4 \mathrm{~mm}$ wide in mid-body, for 37 setigers; $20.5 \mathrm{~mm}$ long, $0.5 \mathrm{~mm}$ wide in thoracic region, $0.6 \mathrm{~mm}$ wide in mid-body, for 47 setigers; $8.9 \mathrm{~mm}$ long, $0.5 \mathrm{~mm}$ wide in thoracic region, $0.6 \mathrm{~mm}$ wide in mid-body, for 37 setigers. Body long, threadlike; thoracic region consisting of 16 closely spaced setigers with weakly elevated notopodial lobes, cylindrical in cross section, slightly swollen; mid-body segments longer than wide, moniliform (Fig. 6B); posterior segments weakly moniliform, with expanded posterior end of nine setigers (Fig. 8D) dorsally rounded and ventrally flattened. Pygidium with ventral cirrus. Color light tan to pink in alcohol.

Prostomium short, conical, nuchal organs not apparent; peristomium $2.4 \times$ as long as wide; with six weakly differentiated annulations (Fig. 8A-B). Dorsal tentacles arising from posterior margin of peristomium; first branchiae posterolateral to dorsal tentacles on distinct asetigerous first segment fused to peristomium, subsequent thoracic branchiae emerging dorsal to notosetal fascicle and shifted middorsally on abdominal setigers (Fig. 8B).

Parapodia low ridges with adjacent notopodial and neuropodial setal fascicles found dorsolaterally in thoracic region and ventrolaterally in abdominal segments (Fig. 8C). Notosetae of 
thoracic region and more anterior setigers of middle segments including 6-7 long, smooth capillaries, these setae transitioning to shorter, flattened capillaries with fine teeth along one edge in middle segments (Fig. 8F), 2-3 smooth capillaries in swollen posterior region; neurosetae with 5-6 smooth capillaries in thoracic region, transitioning to 6-8 shorter, broad bladed setae with fine teeth along cutting edge in middle segments beginning at setiger 41 (Fig. 8E); in narrow posterior body region neurosetae reduced to 3-4 per bundle and becoming smooth capillaries in swollen posterior region. Setal length ratio: 1.5 in thorax, 2.2 in abdomen.

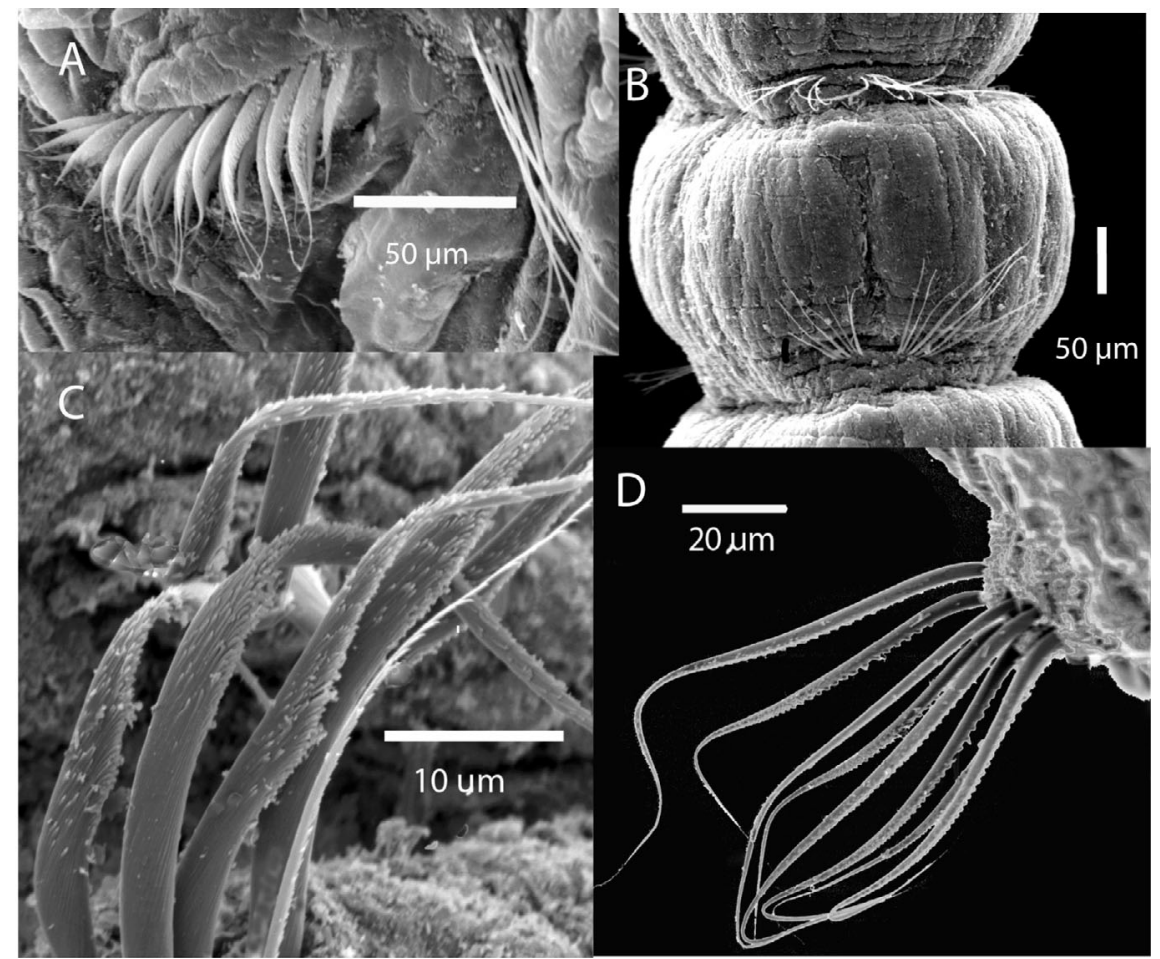

FIGURE 6. Monticellina antelaxa sp. nov. A, neurosetae, posterior setiger. Monticellina giribeti sp. nov. B, moniliform mid-body setigers, lateral view. Monticellina carrikeri sp. nov. C, denticulate posterior neurosetae. Monticellina acunai sp. nov. D, denticulate posterior notosetae.

Methyl green staining. Prostomium and peristomium unstained; thoracic segments uniformly blue except for unstained narrow mid-ventral stripe, remainder of body light green.

Habitat. Collected from the lower intertidal from muddy sand in Gulf of Nicoya.

Remarks. Monticellina giribeti sp. nov. is most similar morphologically to M. elongata sp. nov. (see remarks for M. elongata sp. nov.).

Etymology. This species is named for Professor Gonzalo Giribet, Department of Invertebrate Zoology, Museum of Comparative Zoology, Harvard University, in thanks for his continued support of the work, and his friendship towards, the first author. 
A

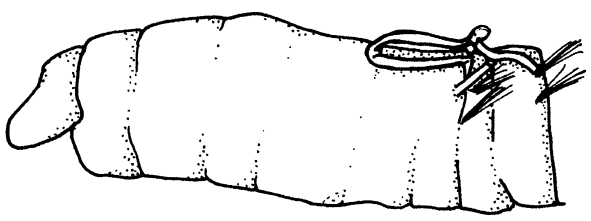

C
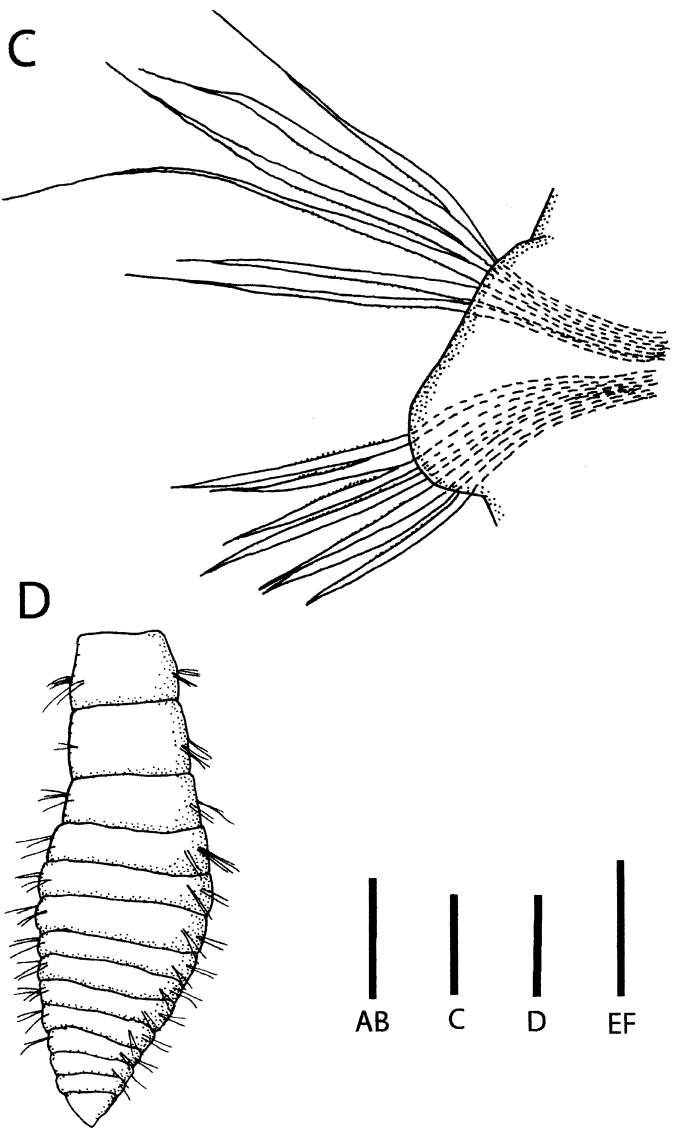

B

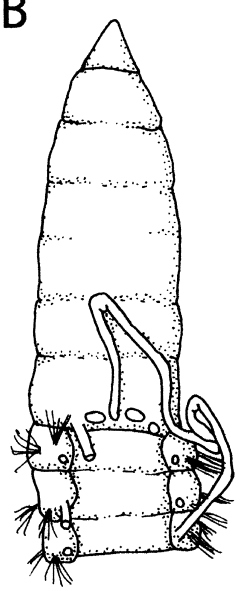

$\mathrm{F}$

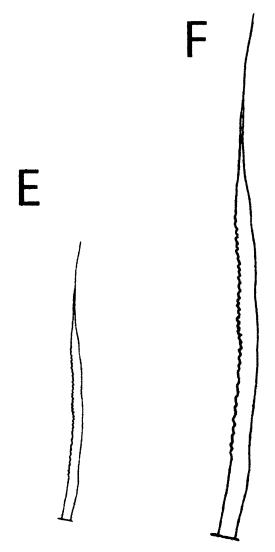

FIGURE 8. Monticellina giribeti sp. nov. A, lateral view of anterior end; b. dorsal view of anterior end; C, posterior setiger, anterior view; $\mathrm{D}$, expanded posterior region, dorsal view. Scale bars: $\mathrm{A}, \mathrm{B}=0.2 \mathrm{~mm} ; \mathrm{C}=0.2$ $\mathrm{mm} ; \mathrm{D}=0.2 \mathrm{~mm} ; \mathrm{E}, \mathrm{F}=20$.

\section{Monticellina setosa sp. nov.}

Figure 9A-D

Monticellina tesselata: Dean 1996a:72; Dean 2004:140 (in part). 
Material examined. Costa Rica, Gulf of Nicoya. Holotype: Sta. 29, 954'55"N, 84²45'15"W, 18 m, muddy sand, 4 Aug 1981 (MCZ 83363). Paratype: same sample (1, MZUCR 177-04).

Comparative material examined. Costa Rica, Gulf of Nicoya. Sta. 29, 9 $9^{\circ} 54^{\prime} 55^{\prime \prime} \mathrm{N}, 84^{\circ} 45^{\prime} 15^{\prime \prime} \mathrm{W}$, 18 m, muddy sand, 4 Aug 1981 (1, HKD).
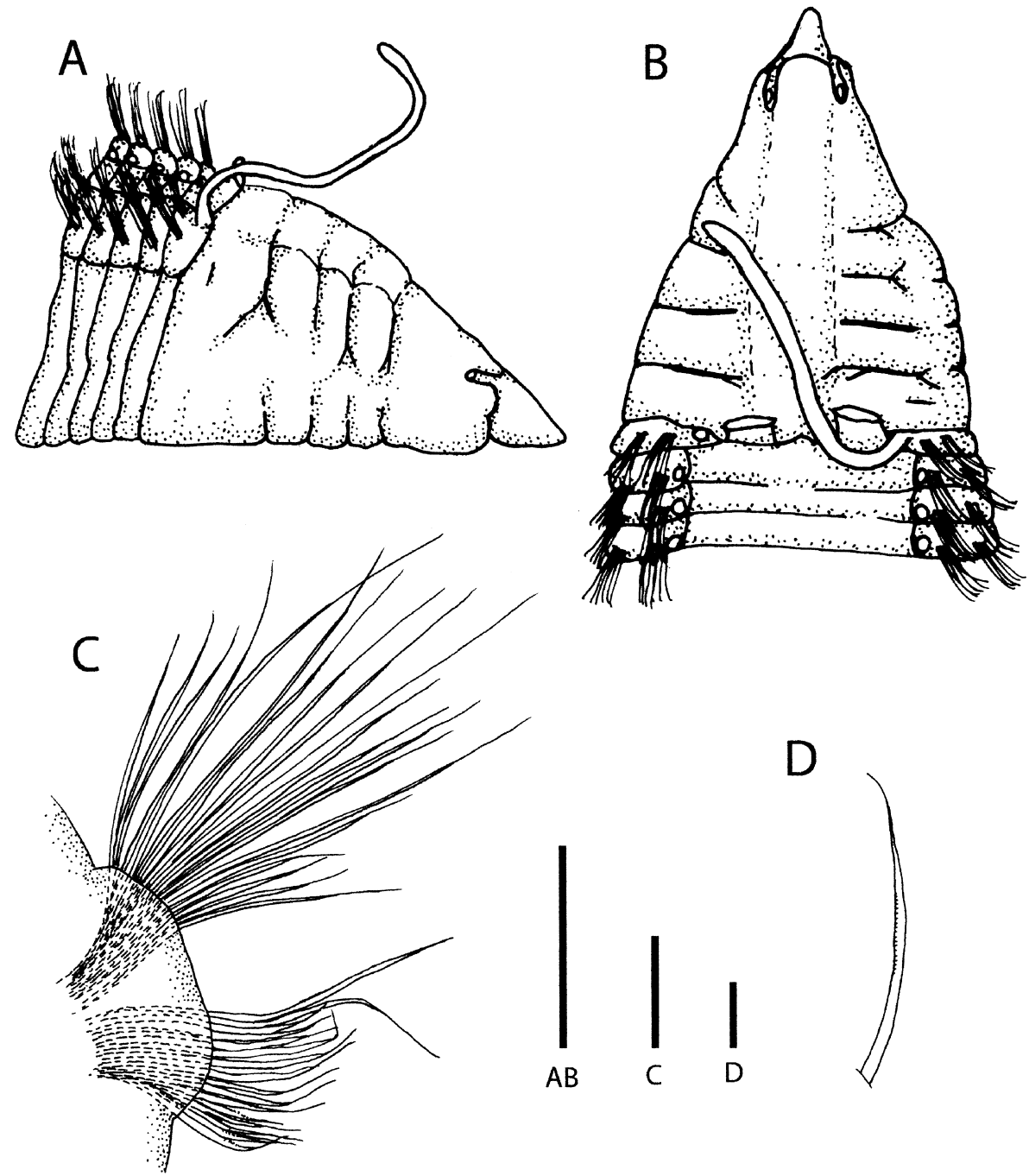

FIGURE 9. Monticellina setosa sp. nov. A, lateral view of anterior end; B, dorsal view of anterior end; C, posterior setiger, anterior view; D, denticulate posterior neuroseta. Scale bars: $\mathrm{A}, \mathrm{B}=0.5 \mathrm{~mm}$; C $=100 \mu \mathrm{m}$; D $=20 \mu \mathrm{m}$.

Description. Holotype nearly complete but lacking pygidium, $15 \mathrm{~mm}$ long, $1.4 \mathrm{~mm}$ maximum width in 60 setiger thoracic region, $0.1 \mathrm{~mm}$ wide in middle and posterior setigers, for 141 total setigers. Paratype (MZUCR 177-04) $24 \mathrm{~mm}$ long, $1.5 \mathrm{~mm}$ maximum width in 70 setigers long, with thoracic region, $0.9 \mathrm{~mm}$ wide in middle and posterior setigers, for 156 total setigers. Thoracic region 
dorsoventrally flattened, setigers $12 \times$ as wide as long, elevated dorsolateral notopodial lobes swollen forming flattened thoracic trough, remainder of body cylindrical in cross section, setigers approximately $0.7 \times$ as wide as long, with low, lateral parapodial lobes. Pygidium of holotype damaged. Color in alcohol light tan with cream-white glandular venter anteriorly; with narrow midventral groove along entire length of body.

Prostomium narrow, conical; with small paired nuchal organs at the posterolateral border in narrow notches overlaid by anterior margin of peristomium (Fig. 9A-B). Peristomium 1.1× as long as wide; partially overlying prostomium anteriorly, with prominent lateral extensions above the oral opening; with prominent dorsal crest; with five asetigerous annulations, each with prominent lateral borders; first annulation $2 \times$ length of annulations $2-4$, subequal in length to fifth annulation. Paired dorsal tentacles emerging from posterior border of last annulation; first pair of branchiae arising lateral to paired tentacles at anterodorsal border of setiger 1 (Fig. 9B), subsequent branchiae arising at posterior edge of notopodial lobes, dorsal to setal fascicles.

Notosetae smooth capillaries throughout, with 6-12 in thoracic region, increasing to 10-20 per fascicle in middle and posterior setigers (Fig. 9C); neurosetae smooth capillaries anteriorly, with 6-8 per fascicle in thoracic region, increasing to 8-16 in middle and posterior fascicles; finely denticulated capillaries appearing ventrally in neurosetal fascicles in posterior body region (approximately setiger 90 in HKD specimen)(Fig. 9D). Setal length ratio: 2.7 in thorax, 1.7 in abdomen.

Methyl green staining. Body staining uniformly light green, prostomium not staining, glandular anterior venter weakly stained.

Habitat. Collected from muddy sand at $18 \mathrm{~m}$ in the Gulf of Nicoya.

Remarks. Monticellina setosa sp. nov. is notable in having 16-20 setae in each fascicle. Only $M$. elongata sp. nov. with up to 16 setae per fascicle approaches this number; however M. elongata sp. nov. has many denticulate setae in both the notopodial and neuropodial fascicles while $M$. setosa sp. nov. has only a few ventral denticulate setae in the neuropodia. There are obvious differences, however, in the morphology of the peristomium of these two species as it is elongate with six annulations in M. elongata sp. nov. and short and wide with five annulations in M. setosa sp. nov. $M$. setosa sp. nov. is unusual in that the nuchal organs are found within a narrow groove formed in the overlying peristomium (Fig. 9A-B). These grooves are not present in other species of Monticellina but Dean \& Blake (2007) reported similar indentations in the peristomium of Caulleriella murilloi Dean \& Blake 2007.

Etymology. This species is named for the high number of notosetae and neurosetae per fascicle in the thorax and abdomen.

\section{Monticellina tesselata (Hartman, 1960)}

Figure 10A-E

Aphelochaeta glandaria: Dean 2004:138.

Aphelochaeta longisetosa: Dean 1996b:83.

Not Tharyx tesselata: Vargas et al. 1985; Maurer et al. 1988.

Not Monticellina tesselata: (Dean 1996a).

Material examined. Costa Rica, Gulfo Dulce. Sta. 3, $8^{\circ} 35^{\prime} \mathrm{N}, 83^{\circ} 16^{\prime} \mathrm{W}, 200 \mathrm{~m}$, soft, black mud, 7 Dec 1993 (1 MZUCR 179-02). Western Santa Barbara Channel, off Point Conception, 115 m, in green mud, 2 paratypes (LACM-AHF Poly 0575). 
Description. Incomplete specimen $12.8 \mathrm{~mm}$ long, $0.5 \mathrm{~mm}$ wide, for 90 setigers. Body long, subequal in width throughout, thorax cylindrical in cross section, middle and posterior setigers dorsoventrally flattened. Thorax with numerous short, crowded segments; parapodial lobes narrow, elongate, notopodial lobes extend above dorsolateral surface forming wide dorsal trough; mid-body with much longer segments, ventrolateral notopodial and neuropodial lobes becoming less pronounced in middle setigers; middorsal ridge present from posterior of peristomium, extending posteriorly along thoracic region, gradually becoming less distinct. Pygidium absent. Color light tan in alcohol.

Prostomium short, conical, with small paired nuchal organs present dorsolaterally at posterior border of peristomium beneath overlying peristomium (Fig. 10A-B). Peristomium as long as wide; two subequal asetigerous annulations present, anterior annulation with several incomplete transverse grooves. Dorsal tentacles emerging from posterior margin of peristomium; first pair of branchiae small, located lateral and slightly posterior to dorsal tentacles on posterior border of setiger 1 medial to notosetal bundle (Fig. 10A), similarly positioned in subsequent setigers.
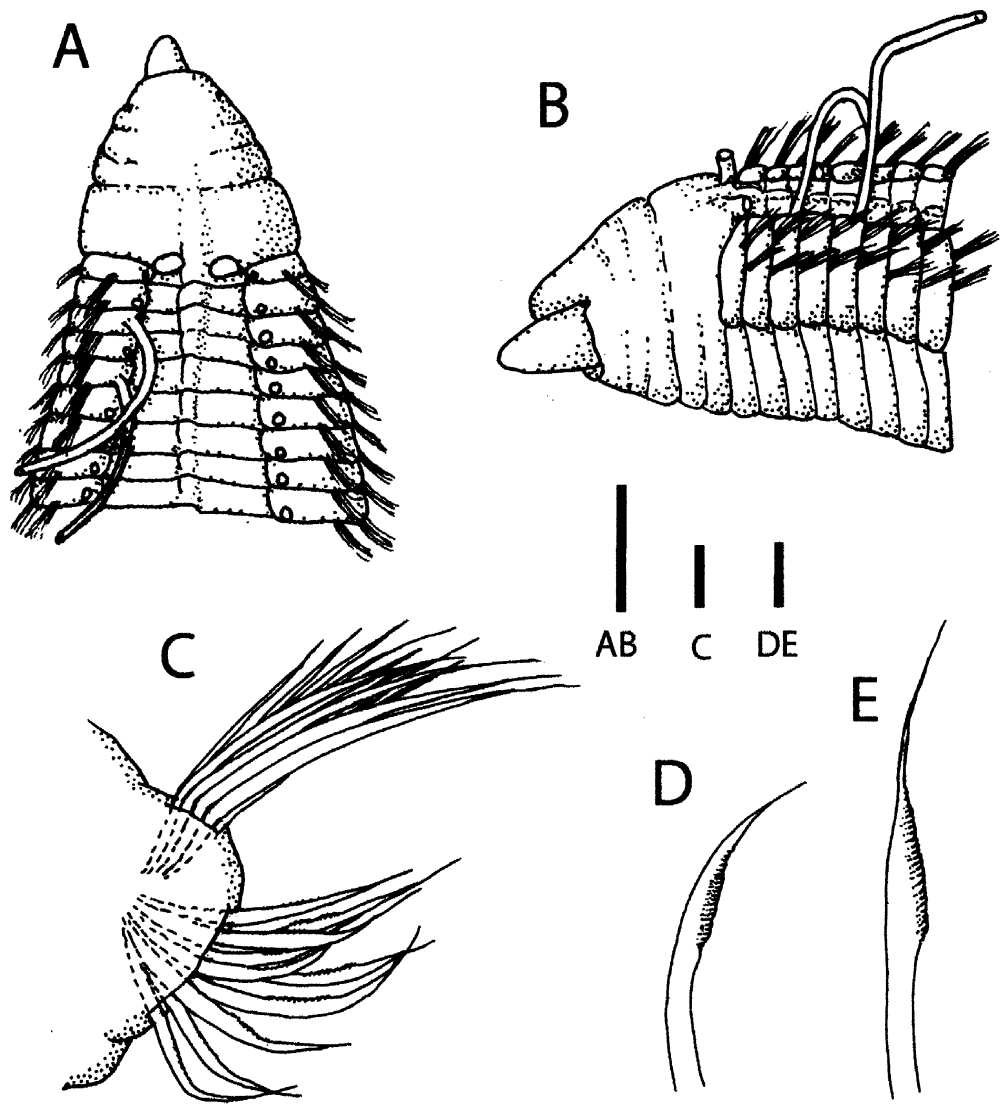

FIGURE 10. Monticellina tesselata Blake, 1996. A, dorsal view of anterior end; B, ventral view of anterior end; C, posterior setiger, anterior view; D-E, denticulate posterior neurosetae. Scale bars: A, B = $0.2 \mathrm{~mm}$; $=$ $50 \mu \mathrm{m} ; \mathrm{D}, \mathrm{E}=10 \mu \mathrm{m}$. 
Notosetae long smooth capillaries arranged in two closely spaced rows throughout, with 4-8 setae per fascicle in thoracic region, increasing to 8-14 in middle and posterior setigers (Fig. 10C). Neurosetae arranged in two rows throughout, with 4-6 setae per fascicle in thoracic region, 6-12 in middle and posterior setigers; blades smooth, wider than those of notosetae, becoming sub-distally widened in mid-thoracic region (setiger 14) with small teeth along cutting edge of blade (Fig. 10D-E). Setal length ratio: 1.3 in thorax, 1.6 in abdomen.

Methyl green staining. Body staining uniformly green, prostomium and middorsal ridge weakly stained.

Habitat. Monticellina tesselata sp. nov. is known from central and southern California in shelf and slope depths (Hartman 1960, 1963; Blake 1996). The range is here extended to similar depths (200 m) off Costa Rica in the tropical eastern Pacific.

Remarks. The middorsal thoracic ridge and the short, wide prostomium and peristomium distinguish this species from the closely related M. siblina Blake (1996) which lacks the ridge and has a large, conical prostomial and peristomial region. M. tesselata sp. nov. also possesses an expanded posterior end which was missing in the Costa Rican specimen. Blake (1996) characterized the peristomium as having 2-3 indistinct annulations but a weakly developed anterior annulation was seen in the Costa Rican specimen and in a paratype of this species (LACM-AHF Poly 0575).

\section{Discussion}

The genus Monticellina was established and referred to the family Ctenodrilidae by Laubier (1961). The type-species, M. heterochaeta Laubier 1961 is a species possessing denticulate capillaries. Laubier (1966) later referred the species to the cirratulid genus Tharyx. Subsequently Blake (1991) revised several genera of bitentaculate cirratulids, including Tharyx, and reestablished the genus Monticellina to include those bitentaculate cirratulids with denticulate capillaries, distinguishing them from species of the genus Tharyx that possessed small-knobbed setae.

Blake (1991) recognized four species within this genus: $M$. dorsobranchialis, $M$. tesselata, $M$. aphelocephala (Hutchings \& Murray, 1984), and M. baptisteae Blake 1991. Two previously described bitentaculate cirratulids with denticulate capillaries, M. heterochaeta and M. annulosa (Hartman, 1965), were placed in synonymy with M. dorsobranchialis by Blake (1991). Blake (1996) later indicated that this synonymy was not correct and that both M. heterochaeta and M. annulosa should be recognized as distinct species. He also recognized five additional species within the genus; M. cryptica, M. luticastella (Jumars, 1975), M. secunda, M. serratiseta (Banse \& Hobson, 1968) and M. siblina. This brought the number of recognized species within the genus Monticellina to eleven.

The unifying characteristic of species of Monticellina is the presence of distinctly serrated capillary setae but, as seen in the previously described species and the new Costa Rican species described here, there is considerable variability in the nature of the serrations (Table 1). Species such as Monticellina acunai sp. nov. (Figs. 1D-E, 6D) and M. elongata sp. nov. (Fig. 7E) have hair-like capillary setae that are coarsely toothed but species such as $M$. giribeti sp. nov. (Fig. 8E-F) and $M$. setosa sp. nov. (Fig. 9D) have hair-like setae with very fine teeth barely visible under oil immersion. $M$. cryptica has more robust setae with weakly developed, widely spaced teeth (Fig. 5E), while $M$. carrikeri sp. nov. (Fig. 4D, 6C) and M. tesselata (Fig. 10DE) have short, subdistally widened setae bearing numerous widely scattered small teeth. Perhaps most unusual are the numerous short, pectinate setae with long fibril-like teeth of M. antelaxa sp. nov. (Figs. 2D, 6A). The species with fine-toothed capillary setae are especially troublesome as SEM analysis of the setae of some species in the genus Aphelochaeta (characterized as possessing only simple capillaries lacking serrations) 


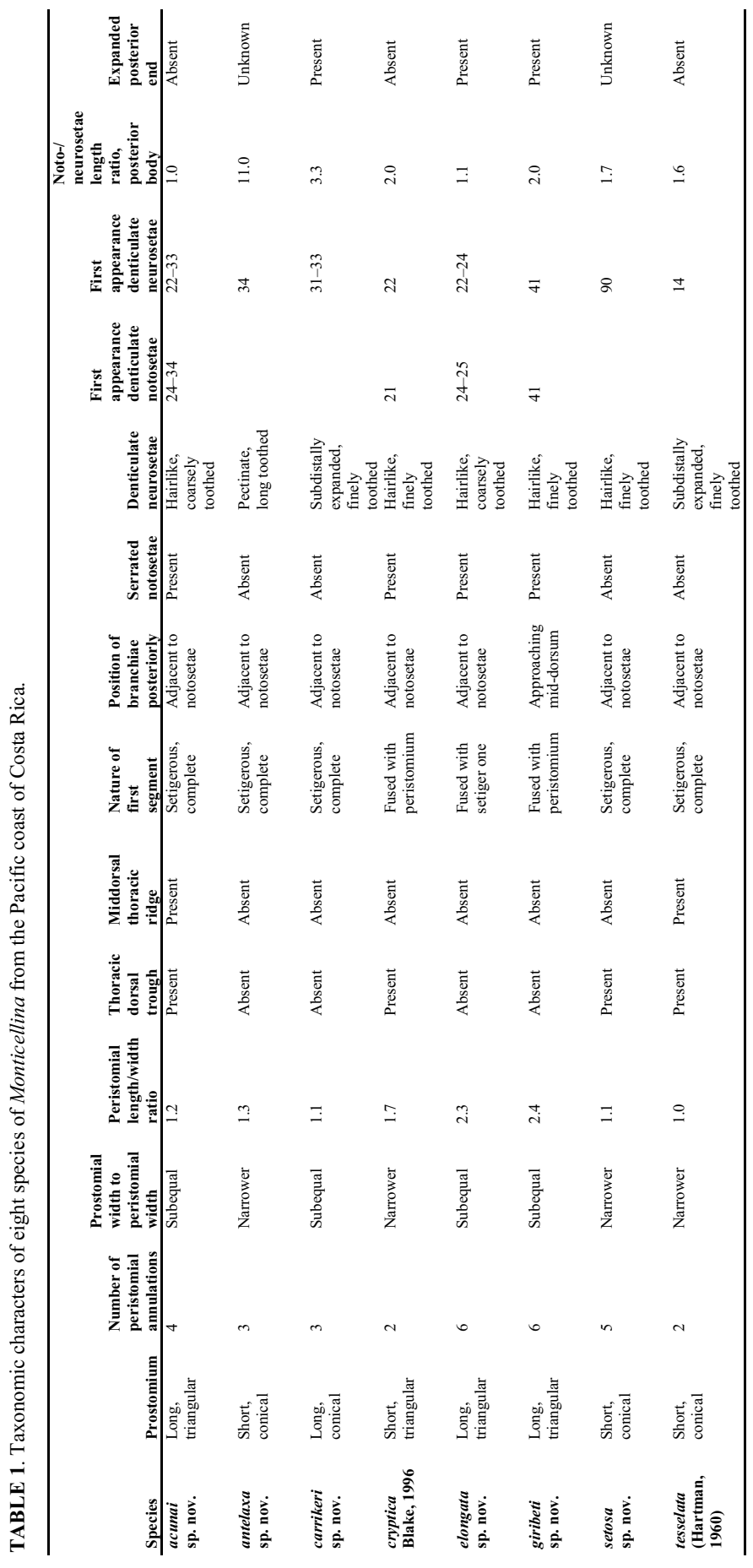


reveal similar fibrillar projections as those of some Monticellina species which are not visible at $1000 \times$ (personal observation, HKD). While recognition of the presence of serrated setae acts as a valuable taxonomic tool it should be regarded as only a tool, not a synapomorphy of a unified taxon.

The morphology of the prostomium and peristomium also shows variability in the Costa Rican species (Table 1). The prostomium of Monticellina acunai sp. nov. (Fig. 1A), M. carrikeri sp. nov. (Fig. 4B), M. elongata sp. nov. (Fig. 7B), and M. giribeti sp. nov. (Fig. 8B) is approximately as wide at its posterior as the adjacent peristomium but in M. antelaxa sp. nov. (Fig. 2A), M. cryptica (Fig. 5B), M. setosa sp. nov. (Fig. 9B) and M. tesselata (Fig. 10A) the prostomium is relatively more narrow. M. acunai sp. nov. (Fig. 1A), M. antelaxa sp. nov. (Fig. 2A), M. carrikeri sp. nov. (Fig. 4B), M. setosa sp. nov. (Fig. 9B), and M. tesselata (Fig. 10A) all have a rather wide peristomium relative to peristomial length while the peristomium of M. elongata sp. nov. (Fig. 7B), M. giribeti sp. nov. (Fig. 8B), and M. cryptica (Fig. 5B) is noticeably longer than wide. A previously described species of Monticellina, M. luticastella, has an even more truncated peristomial region (Blake 1996, Fig. $8.23 \mathrm{~A}$ ) than any of the Costa Rican species. Neither the shape of the prostomium or peristomium can be used to characterize the genus Monticellina.

Dean \& Blake (2007) discussed the occurrence of asetigerous annulations of the peristomium in species of Chaetozone and Caulleriella from Costa Rica and pointed out the validity of these structures as a species-level character. Similar species-specific peristomial annulations occur in Monticellina species and may be considered as a legitimate differential character but these annulations are highly variable within the taxon (Table 1). Again, there is variation in the number of peristomial annulations in the Costa Rican species of Monticellina. While two of the three species with an elongate peristomium have five (M. giribeti sp. nov., Fig. 8B) and six (M. elongata sp. nov., Fig. 7B) peristomial annulations, $M$. cryptica has only two with the second being much longer than the first (Fig. 5B). There is no noticeable trend in the number of peristomial annulations in the Costa Rican species.

Parapodial morphology as well as the notosetal/neurosetal length ratio does not provide a useful method to characterize species of Monticellina. Generally the parapodial lobes are short raised tori (Fig. 7C) or the setal fascicles emerge directly from the body wall (Fig. 4E). The notosetal and neurosetal fascicles of the Costa Rican species are all adjacent, usually with a decided gap between the bundles as seen in many other genera of bitentaculate cirratulids with the exception of Caulleriella (Blake 1996, Dean \& Blake 2007). The ratio of the longest notoseta to the longest neuroseta on a segment ranges in the Costa Rican material from 11:1 in the abdominal region of $M$. antelaxa sp. nov. (Fig. 2C) to 1.0 in M. acunai sp. nov. (Fig. 1F). This ratio is variable within the genus and is not unlike the ratios seen in other bitentaculate genera.

The genus Monticellina, as currently defined, is a perplexing group of species and is likely not to be monophyletic. The unifying characteristic of denticulate capillary setae is not a consistent and definitive character given the differences in the nature of the dentition among species. Also, as shown above, the nature of the prostomium, peristomium, parapodia, and relative setal lengths provide no synapomorphy for this genus. A more detailed analysis of this genus is planned to achieve a better understanding of the relationships within this taxon. It may be that Monticellina and the morphologically similar genus Aphelochaeta may be interrelated but the resolution of that issue may require the results of molecular studies. The recognition of all bitentaculate Cirratulidae possessing denticulate capillary setae as belonging to the genus Monticellina is important in the identification of local species even if it may not fully differentiate a monophyletic group.

The identification of six previously undescribed species of Monticellina from the Pacific coast of Costa Rica illustrates the considerable species richness of the Cirratulidae. Dean \& Blake (2007) drew the same conclusion after describing eight new species in the genera Chaetozone and 
Caulleriella from Costa Rica. There have been few analyses of cirratulids from the Central American Eastern Pacific so the discovery of undescribed species is not unexpected. An additional explanation for the great diversity of cirratulid species encountered is that the morphology of cirratulid setae had not been carefully examined until the work of Blake $(1991,1996)$. Many species are poorly known and have been misinterpreted. Many of the cirratulid species reported to be cosmopolitan (e.g., Chaetozone setosa Malmgren, 1867; Caulleriella alata Southern, 1914) have been found to be composed of numerous separate species lumped together as a result of incomplete species descriptions and lack of careful investigation. Recent studies of the Cirratulidae provide numerous new species descriptions and suggest that the family may prove to be one of the more speciose among the Polychaeta.

The presence of Monticellina cryptica and M. tesselata in Costa Rica, two species previously reported from California (USA) from shelf and slope depths, indicates that some species of Cirratulidae have a wider geographic range than previously believed. Dean \& Blake (2007) reported a similar increase in geographic range for Chaetozone corona Berkeley and Berkeley, 1941 and $C$. hedgpethi Blake, 1996, both of which had also previously been collected only from California (USA). A better understanding of species distributions of these bitentaculate cirratulids will require more extensive sampling of both shallow coastal and shelf depth waters along the Eastern Pacific.

\section{Acknowledgements}

The collections of specimens from Costa Rica could not have been made without the help of Prof. José A. Vargas and Prof. Jenaro Acuña, both of Centro de Investigaciones en Ciencias del Mar y Limnologia (CIMAR). Some of these collecting trips were supported by the Costa Rica-United States of America (CR-USA) Foundation for Cooperation through grants to Prof. José A. Vargas. Scanning Electron Microscopy (SEM) was conducted at the Center for Imaging and Mesoscale Structures, Department of Organismic and Evolutionary Biology at Harvard University with the guidance of Richard Schalek. This study was supported by the National Science Foundation under Grant No. DEB-0118693 (PEET) to James A. Blake, University of Massachusetts, Boston. This is a contribution of the Centro de Investigación en Ciencias del Mar y Limnologia (CIMAR), Universidad de Costa Rica. We acknowledge the valuable analysis of this manuscript by Dr. Nancy J. Maciolek , Editor of the IPC9 Conference Proceedings, and the review by Susan J. Chambers (Marine Invertebrate Section, National Museums of Scotland), both of which greatly improved this paper.

\section{References}

Banse, K. \& Hobson, K.D. (1968) Benthic polychaetes from Puget Sound, Washington. Proceedings of the United States National Museum, 125(3667), 1-53.

Berkeley, E. \& Berkeley, C. (1941) On a collection of Polychaeta from the west coast of Vancouver Island. Contributions to Canadian Biology, Ottawa, new series, 7, 309-318.

Blake, J.A. (1991) Revision of some genera and species of Cirratulidae (Polychaeta) from the western North Atlantic. Ophelia Supplement 5, 17-30.

Blake, J.A. (1996) Family Cirratulidae Ryckholdt, 1851. Including a revision of the genera and species from the Eastern North Pacific. In J. A. Blake, B. Hilbig \& P. H. Scott (eds.), Taxonomic atlas of the benthic fauna of the Santa Maria Basin and western Santa Barbara Channel, Volume 6. The Annelida, Part 3. Santa Barbara 
Museum of Natural History, Santa Barbara, California, pp. 263-384.

Dean, H.K. (1996a) Subtidal benthic polychaetes (Annelida) of the Gulf of Nicoya, Costa Rica. Revista Biologia Tropical, 44 (Suppl. 3), 69-80.

Dean, H.K. (1996b) Polychaete worms (Annelida) collected in Golfo Dulce during the Victor Hensen Costa Rica expedition (1993/1994). Revista Biologia Tropical, 44 (Suppl. 3), 81-86.

Dean, H.K. (2004) Marine biodiversity of Costa Rica: Class Polychaeta (Annelida). Revista Biologia Tropical, 52 (Suppl. 2), 131-181.

Dean, H.K. \& J.A. Blake (2007) Chaetozone and Caulleriella (Polychaeta: Cirratulidae) from the Pacific Coast of Costa Rica, with description of eight new species. Zootaxa, 1451, 41-68.

Hartman, O. (1960) Systematic account of some marine invertebrate animals from the deep basins of Southern California. Allan Hancock Pacific Expeditions, 22, 69-215.

Hartman, O. (1963) Submarine canyons of Southern California Part III. Systematics: Polychaetes. Allan Hancock Pacific Expeditions, 27(3), 1-93.

Hartman, O. (1965) Deep-water benthic polychaetous annelids off New England to Bermuda and other North Atlantic areas. Allan Hancock Foundation Occasional Paper, 28, 1-378.

Hutchings, P. \& Murray, A. (1984) Taxonomy of polychaetes from the Hawkesbury River and the southern estuaries of New South Wales, Australia. Records of the Australian Museum, 36 (Supple. 3), 1-118.

Jumars, PA (1975) Target species for deep-sea studies in ecology, genetics, and physiology. Zoological Journal of the Linnaean Society, 57, 341-348.

Kirkegaard, J. (1959) The Polychaeta of West Africa. Atlantide Report, No. 5, 7-117.

Laubier, L. (1961) Monticellina heterochaeta n. g., sp. nov., Cténodrilidé (Polychétes sédentaires) des vases cotières de Banyuls-sur-Mer. Vie et Milieu, 11, 601-604.

Laubier, L. (1966) Sur la position systématique de Monticellina heterochaeta Laubier, 1961. Bulletin de la Societe zoologique de France, 91, 631-638.

Malmgren, A. J. (1867) Annulata Polychaeta Spetsbergiae Groenlandiae, Islandiae et Scandinaviae hactenus cognita. Öfversigt af Kongliga Vetenskaps-Akademien förhandlingar, 24, 127-235.

Maurer, D. \& Vargas, J.A. (1984) Diversity of soft-bottom benthos in a tropical estuary: Gulf of Nicoya, Costa Rica. Marine Biology, 81, 97-106.

Maurer, D., Vargas, J.A. \& Dean, H. (1988) Polychaetous annelids from the Gulf of Nicoya, Costa Rica. Internationale Revue gesamten Hydrobiologie, 73, 43-59.

Morales-Ramírez, A. (1996) Checklist of copepods from Gulf of Nicoya, Coronado Bay and Golfo Dulce, Pacific coast of Costa Rica, with comments on their distribution. Revista Biologia Tropical, 44 (Supple. 3), 103-113.

Southern, R. (1914) Claire Island Survey Part 47. Archiannelida and Polychaeta. Proceedings of the Royal Irish Academy, 31, 1-160.

Vargas, J.A., Dean, H.K., Maurer, D. \& Orellana, P. (1985) Lista preliminar de invertebrados associados a los sedimentos del Golfo de Nicoya, Costa Rica. Brenesia, 24, 327-342. 